\title{
Urine neutrophil gelatinase-associated lipocalin and urine output as predictors of the successful discontinuation of continuous renal replacement therapy in critically ill patients with acute kidney injury
}

Josefine Thomsen $^{1 *}$ (D) Ulrik Sprogøe ${ }^{2}$ and Palle Toft ${ }^{1}$

\begin{abstract}
Background: Continuous renal replacement therapy (CCRT) is a frequently used modality for the support of intensive care patients with acute kidney injury (AKI). Nevertheless, there are no objective criteria for the discontinuation of CRRT. The purpose of this study was to investigate whether urine neutrophil gelatinase-associated lipocalin (UNGAL) alone or in combination with urine output could be used as a diagnostic test for renal function recovery in ICU patients on CRRT.

Methods: This was a single-centre prospective observational study including patients with acute kidney failure needing CRRT. Sixty-nine patients were enrolled, and 54 completed the study. Of the 54 patients, 22 recovered renal function (REC), defined as dialysis independency at $72 \mathrm{~h}$ from discontinuation, while 32 patients did not (NREC). Urine NGAL was measured at 0, 6, 12, and $24 \mathrm{~h}$ after CRRT discontinuation. The cumulated urine output was measured for $24 \mathrm{~h}$ prior to discontinuation and at 6, 12, and $24 \mathrm{~h}$ after discontinuation. Missing UNGAL values were calculated by interpolation. The Youden's index was used to calculate cut-off values in order to define UNGAL and urine output single variable and 2-variable diagnostic tests with the optimum prediction of successful CRRT discontinuation.
\end{abstract}

Results: Baseline characteristics at CRRT initiation were similar between groups. Compared to the NREC group, the REC group had significantly higher urine output $(p<0.0001)$ and lower UNGAL $(p<0.001)$ at all time points, except for UNGAL at $24 \mathrm{~h}(p<0.24)$. The best UNGAL predictor for successful CRRT discontinuation was UNGAL at $6 \mathrm{~h}$ after discontinuation (predictive value 80\%). The best single predictor was cumulated urine output $24 \mathrm{~h}$ before discontinuation (predictive value 85\%). The combinations of UNGAL at $6 \mathrm{~h}$ (cut-off $1650 \mathrm{\mu g} / \mathrm{L}$ ) with cumulated urine output $24 \mathrm{~h}$ prior to discontinuation (cut-off $210 \mathrm{ml}$ ) proved to be the superior tests (using either "or" or "and"), with predictive values of 93\% (successful CRRT discontinuation) and 92\% (dialysis dependency).

Conclusions: With a predictive value of $93 \%$, the combination of UNGAL at $6 \mathrm{~h}$ after and the cumulated urine output $24 \mathrm{~h}$ prior to CRRT cessation proved to be the best diagnostic test for successful CRRT discontinuation in ICU patients.

(Continued on next page)

\footnotetext{
* Correspondence: Josefine.thomsen@rsyd.dk

'Department of Anaesthesiology and Intensive Care, Odense University Hospital, Odense, Denmark

Full list of author information is available at the end of the article
}

(C) The Author(s). 2020 Open Access This article is licensed under a Creative Commons Attribution 4.0 International License, which permits use, sharing, adaptation, distribution and reproduction in any medium or format, as long as you give appropriate credit to the original author(s) and the source, provide a link to the Creative Commons licence, and indicate if changes were made. The images or other third party material in this article are included in the article's Creative Commons licence, unless indicated otherwise in a credit line to the material. If material is not included in the article's Creative Commons licence and your intended use is not permitted by statutory regulation or exceeds the permitted use, you will need to obtain permission directly from the copyright holder. To view a copy of this licence, visit http://creativecommons.org/licenses/by/4.0/ The Creative Commons Public Domain Dedication waiver (http://creativecommons.org/publicdomain/zero/1.0/) applies to the data made available in this article, unless otherwise stated in a credit line to the data. 
(Continued from previous page)

Clinical trial registration: N/A

Keywords: Renal replacement therapy, Critical care, Acute kidney injury, Intensive care unit, Dialysis, Urine neutrophil gelatinase-associated lipocalin

\section{Background}

Acute kidney injury (AKI) is a common complication in patients admitted to an intensive care unit (ICU). An international multicentre study found that $13.5 \%$ of patients admitted to the ICU required renal replacement therapy (RRT) [1]. The preferred choice of dialysis modality is continuous renal replacement therapy (CRRT), thereby obtaining better solute control and more stable haemodynamics. However, despite the frequent use of CRRT, there is no consensus regarding its discontinuation. Ideally, the physician would have access to a test with high diagnostic sensitivity for predicting renal recovery. This is, however, complicated by the complex physiology and individualized presentation of the critically ill patient. In clinical practice, CRRT is discontinued on an individual basis, i.e., when the physician assesses that the general state of the patient could indicate renal recovery. Urine output is currently the most valid predictor for successful discontinuation [2-6]. Other less predictive variables are serum and urine creatinine, Sequential Organ Failure Assessment (SOFA) score, dialysis time, age, co-morbidities, and 2-h creatinine clearance [2-7]. In recent years, specific biomarkers have been associated with renal injury and renal recovery. Currently, the most promising and thoroughly explored biomarker is neutrophil gelatinase-associated lipocalin (NGAL). NGAL has already been shown to be a very early predictor of AKI [8-13]. In cases in which the duration of trauma to the kidney is known, such as following organ transplantation and cardiac surgery, NGAL has shown excellent results. The landmark trial by Mishra and colleagues [11] from 2005 showed that urine NGAL (uNGAL) $2 \mathrm{~h}$ after cardiopulmonary bypass had an area under the receiver operating curve (ROC) of $99.8 \%$ for the prediction of AKI. In the same study, the serum creatinine increased with a 1-3 day delay. Urine NGAL is an expression of ongoing damage to the kidney, whereas creatinine reflects the function of the kidney. A decrease in uNGAL might therefore represent renal recovery. Few studies have focused on the ability of UNGAL to predict renal recovery in critically ill patients at the time of discontinuation of dialysis [14-16]. In these studies, uNGAL was determined $24 \mathrm{~h}$ or later after discontinuation. It may be argued that the longer the timeframe from discontinuation until the UNGAL level is determined, the less clinically relevant the biomarker becomes.
The objectives of the present study were to investigate whether uNGAL as a diagnostic test in the interval 0$24 \mathrm{~h}$ after discontinuation of CRRT is able to predict renal recovery in critically ill patients, and whether a diagnostic test combining UNGAL with urine output could be an even better predictor of renal recovery.

\section{Methods \\ Setting}

This single-centre prospective observational study was conducted in the tertiary ICU at Odense University Hospital between May 2016 and April 2018. Patients with AKI, according to the RIFLE criteria, who were admitted to the ICU were included at the start of CRRT. The exclusion criteria were age $<18$ years, chronic kidney failure and missing consent. Patient follow-up was 3 months after discharge from the ICU. The decision as to when to initiate/discontinue CRRT was at the discretion the ICU physicians on duty, and it was based on the complex physiology and individualized presentation of the critically ill patient/critically ill patient in recovery.

Continuous veno-venous haemodialysis (CVVHD) was the preferred renal replacement modality with multifiltrate $\mathrm{CiCa}$ dialysate (Fresenius Medical Care, Bad Homburg, Germany). If the patient was otherwise ready to be transferred to a regular clinical ward, haemodialysis (HD) was initiated instead of CRRT, i.e., HD was usually initiated at the clinical ward or shortly before transfer out of the ICU.

\section{Endpoint}

The successful endpoint with regard to the diagnostic test of uNGAL and urine output was defined as 3 dialysis-free days $(72 \mathrm{~h})$ following the discontinuation of CRRT.

\section{Data collection}

Demographic and basic clinical information together with a baseline urine sample for uNGAL analysis were obtained at study inclusion. Serum creatinine $(\mathrm{S}-\mathrm{Cr})$ and CRP at inclusion (Table 1) refer to samples from 06.00 a.m. of the calendar day of CRRT initiation. For patients who were admitted later than 06:00 a.m. and initiated CRRT the same day, S-Cr and CRP at the time of ICU admission were used.

At the time of the first cessation of CRRT, the following physiological and laboratory variables were collected: 
Table 1 Baseline characteristics at continuous renal replacement therapy initiation

\begin{tabular}{|c|c|c|c|c|}
\hline Clinical variables & Recovery $(n=22)$ & $\begin{array}{l}\text { Non-recovery; CRRT } \\
\text { re-initiation }(n=20)\end{array}$ & $\begin{array}{l}\text { Non-recovery; Haemodialysis } \\
\text { initiation }(n=12)\end{array}$ & $P$-value \\
\hline Male/female & $16 / 6(73 \% / 27 \%)$ & $11 / 9(55 \% / 45 \%)$ & $9 / 3(75 \% / 25 \%)$ & 0.56 \\
\hline Age, years & 77 [42-83] & $70[51-81]$ & 68 [30-83] & 0.84 \\
\hline $\mathrm{BMl}, \mathrm{kg} / \mathrm{m}^{2}$ & 26 [19-35] & 27 [19-38] & $25[24-37]$ & 0.45 \\
\hline SOFA, highest value & 13 [7-18] & 15 [11-19] & $13[8-21]$ & 0,20 \\
\hline APACHE ॥ & 27 [18-40] & $29[21-43]$ & 26 [18-38] & 0.71 \\
\hline SAPS ॥ & $56[30-75]$ & $65[44-86]$ & $58[38-78]$ & 0.10 \\
\hline Hypertension & $9(41 \%)$ & $11(55 \%)$ & $7(58 \%)$ & 0.76 \\
\hline Malignity & $6(27 \%)$ & $10(50 \%)$ & $2(17 \%)$ & 0.56 \\
\hline $\mathrm{CWH} / \mathrm{CWHD}$ & $0 / 22(0 / 100 \%)$ & $4 / 16(20 / 80 \%)$ & $0 / 12(0 / 100 \%)$ & 0.14 \\
\hline RIFLE-F & $21(95 \%)^{\mathrm{a}}$ & $20(100 \%)$ & $12(100 \%)$ & 0.41 \\
\hline Furosemide, mg/day & $0[0-554]$ & $80[0-534]$ & $100[0-480]$ & $0.44^{d}$ \\
\hline Mean arterial pressure, $\mathrm{mmHg}$ & $69[62-85]$ & 70 [63-93] & 78 [59-113] & 0.23 \\
\hline Creatinine, $\mu \mathrm{mol} / \mathrm{L}$ & $186[84-621]$ & $194[87-531]$ & $238[90-765]$ & 0.99 \\
\hline Creatinine clearance, $\mathrm{ml} / \mathrm{min}$ & 19 [7-45] & 15 [8-27] & $17[5-26]$ & 0.11 \\
\hline C-Reactive Protein (CRP), mg/L & $216[7-454]$ & $139[13-266]$ & $108[34-423]$ & 0.18 \\
\hline Urine output, $\mathrm{ml} /$ hour $^{\mathrm{b}}$ & $18[0-50]$ & 8 [0-97] & $0[0-52]$ & $0.40^{\mathrm{d}}$ \\
\hline Urine output, $\mathrm{ml} /$ day ${ }^{\mathrm{c}}$ & 398 [103-1488] & $326[8-1750]$ & $120[13-2550]$ & $0.23^{d}$ \\
\hline Noradrenaline, $\mu \mathrm{g} / \mathrm{kg} / \mathrm{min}$ & $0.35[0.09-1.26]$ & $0.28[0.07-1.32]$ & $0.12[0.02-1.10]$ & $0.35^{\mathrm{d}}$ \\
\hline Nephrotoxic medicine including contrast. & $8(36 \%)$ & $12(60 \%)$ & $6(50 \%)$ & 0.18 \\
\hline Presumed primary cause of AKI: & & & & 0.56 \\
\hline Prerenal & $8(36 \%)$ & $5(25 \%)$ & $2(17 \%)$ & \\
\hline Sepsis & $12(55 \%)$ & $13(65 \%)$ & $4(33 \%)$ & \\
\hline Glomerulonephritis & 0 & 0 & $1(8 \%)$ & \\
\hline Rhabdomyolysis & $1(4,5 \%)$ & $1(5 \%)$ & $3(25 \%)$ & \\
\hline Microthrombosis/vasculitis & $1(4,5 \%)$ & $1(5 \%)$ & $2(17 \%)$ & \\
\hline Primary reason for ICU admission: & & & & 0.62 \\
\hline Septic shock/sepsis & $9(41 \%)$ & $103(65 \%)$ & $6(51 \%)$ & \\
\hline Trauma & $1(5 \%)$ & $2(10 \%)$ & 0 & \\
\hline AKI & $5(23 \%)$ & $1(5 \%)$ & $2(17 \%)$ & \\
\hline Respiratory failure & $4(18 \%)$ & $2(10 \%)$ & $3(34 \%)$ & \\
\hline Low cardiac output & $3(14 \%)$ & $2(10 \%)$ & $1(8 \%)$ & \\
\hline Urine-NGAL, $\mu \mathrm{g} / \mathrm{L}$ & $2645[279-27,543]$ & 2894 [749-18,537] & $3619[128-30,170]$ & $0.57^{d}$ \\
\hline $\begin{array}{l}\text { Time, ICU admission to CRRT initiation/study } \\
\text { inclusion, days }\end{array}$ & $1[0-7.4]$ & $2[0-5.9]$ & $1[0-12.1]$ & 0.94 \\
\hline
\end{tabular}

P-value was calculated between the recovery and non-recovery (CRRT-re-initiation and haemodialysis) groups. CRRT, continuous renal replacement therapy; SAPS II, Simplified Acute Physiology Score II; SOFA, Sequential Organ Failure Assessment; APACHE II, Acute Physiology and Chronic Health Evaluation II; CVVH, continuous venovenous haemofiltration; CVVHD, continuous veno-venous haemodialysis; AKI, acute kidney injury; NGAL, neutrophil gelatinase-associated lipocalin. Categorical variables are expressed as numbers (percentages). Continuous variables are expressed as medians [10-90\% quantiles]

a) RIFLE-I was recorded for one patient. b) Mean urine output $6 \mathrm{~h}$ before dialysis initiation; if urine output $<5 \mathrm{ml}$ in one hour, then it was recorded as $0 \mathrm{ml}$. c) Urine output $24 \mathrm{~h}$ before CRRT initiation. d) Log10 transformation was used to calculate the p-value

uNGAL at the time of cessation $(0 \mathrm{~h})$ and at 6,12 , and 24h (uNGAL 0 h, uNGAL 6 h, uNGAL 12 h, uNGAl 24 h) thereafter; mean arterial pressure at $0,6,12$ and $24 \mathrm{~h}$; use of diuretics at 6,12 , and $24 \mathrm{~h}$ (note that in our ICU unit, diuretics are not given during CRRT treatment); s$\mathrm{Cr}$, creatinine clearance, and CRP at 0 and $24 \mathrm{~h}$; cumulated urine output for $24 \mathrm{~h}$ prior to CRRT cessation (UOC24pre) and $24 \mathrm{~h}$ after CRRT cessation (UOC24post); average hourly urine output during the first $6 \mathrm{~h}$ (UOA6) and during the first $12 \mathrm{~h}$ (UOA12) after cessation; and the time from CRRT cessation until the re-initiation of CRRT. 


\section{Outcome data}

The outcomes were dialysis dependence and mortality at 3 months after ICU discharge.

\section{Urine NGAL collection and analysis}

Urine specimens for analysing UNGAL were collected primarily from the urinary catheter and, if that was not possible, from the urinary catheter bag. The urine sample was immediately transferred to a $-80^{\circ} \mathrm{C}$ freezer.

Urine NGAL was measured using an automated, turbidimetric immunoassay (NGAL Test Reagent Kit, BioPorto Diagnostics, Denmark) on a Roche cobas 8000 analyser (Roche Diagnostics, Rotkreutz, Switzerland). The $95 \%$ reference range for uNGAL $(4.3-204 \mu \mathrm{g} / \mathrm{L})$ was based on UNGAL measurements in 50 healthy adults (laboratory staff and their family members, 25 males and 25 females) aged 21-66 years using the same uNGAL method as employed in the study.

\section{Data processing and analysis}

Study data were managed using REDCap (REDCap Consortium, Vanderbilt University Medical Center, Nashville, TN) electronic data capture tools in the Odense Patient Data Explorative Network (OPEN), hosted by the University of Southern Denmark and Odense University Hospital. All data were transferred to Excel 16 (Microsoft, Redmond, WA) for Mac and analysed using JMP 14.1 (SAS Institute, Cary, North Carolina) statistical software.

To validate the diagnostic tests for the successful discontinuation of CRRT, the patients were divided into the "recovery" (REC) and "non-recovery, all" (NREC-A) groups. Successful recovery was defined as the patient being independent from dialysis for at least $72 \mathrm{~h}$. The NREC-A group was subdivided according to whether the patient initiated haemodialysis (NREC-H) or reinitiated CRRT (NREC-C). The patients were excluded from analysis if they had died before discontinuation or if active treatment of the patient's basic condition had been discontinued while they were on CRRT. Each patient was included only once.

Demographic variables and variables at discontinuation were compared between the REC and NREC-A groups using Student's t-tests and Wilcoxon nonparametric tests for continuous variables. Fisher's exact tests were used for categorical variables. $p<0.05$ was considered statistically significant.

The NGAL values were shown to be log-normally distributed. Linear regression analysis of the correlations between $\log$ uNGAL at $6 \mathrm{~h}$ and $\log$ uNGAL at $12 \mathrm{~h}$ and between $\log$ uNGAL 6 at hours and log UNGAL at $0 \mathrm{~h}$ was used to calculate the missing UNGAL $6 \mathrm{~h}$ values or missing uNGAL $0 \mathrm{~h}$ values by interpolation.
For all uNGAL (at 0, 6, 12 and $24 \mathrm{~h}$ ) and urine output (UOC24pre, UOC24post, OUA6 and OUA12) measures, the area under the receiver operating characteristic (ROC) curve, sensitivity, specificity, the negative predictive value (NPV), and the positive ("positive" outcome defined as the patient being dialysis dependent) predictive value (PPV) were calculated using Excel 16 (Microsoft, Redmond, WA) and Prism 8 (GraphPad, San Diego, $\mathrm{CA}$ ). Youden's indices (defined as sensitivity + specificity - 1,00) were calculated to determine the optimum cutoff values, i.e. highest combined sensitivity and specificity. Each of the identified UNGAL and urine output optimum cut-off values were permutated in "and" and "or" expressions to identify the combination of the 2 variables yielding the highest sensitivity or NPV [17], i.e., a "test" based on UNGAL and urine output, if negative, giving the best prediction of renal function recovery, i.e., successful CRRT discontinuation.

To estimate the increase in diagnostic performance of 2-variable models in comparison with the relevant single variable models, net classification index (NRI) was calculated as (sensitivity + specificity [2-variable model]) (sensitivity + specificity [single variable model]), with a positive value indicating higher diagnostic performance of the 2-variable model.

\section{Results}

Sixty-nine patients were enrolled in the study. A total of 262 patients were treated with CRRT at the Odense University Hospital during the 2 -year study period. A total of 193 (74\%) patients were excluded, either because they did not meet the inclusion criteria or because of failure to collect urine within the inclusion window. In addition, 15 out of the $69(22 \%)$ patients died while on CRRT. Of the remaining 54 patients, 22 (41\%) experienced renal function recovery (REC), whereas $32(59 \%)$ patients did not recover renal function (NREC-A). This NREC-A group of 32 was further subdivided into the NREC-C (20 [63\%] patients) and NREC-H (12 [37\%] patients) subgroups (Fig. 1). One patient in the REC group was placed back on CRRT after $92 \mathrm{~h}$ of dialysis independence.

The baseline characteristics of the three groups, REC, NREC-H, and NREC-C, are summarized in Table 1 . The median age, sex, and number of comorbidities were similar among the groups. Table 2 shows the variables at the time of and following the discontinuation of CRRT. The REC group had significantly lower uNGAL levels at 0,6 , and $12 \mathrm{~h}$ after CRRT discontinuation compared to the NREC-A group. The average UO6, UO12, UOC24post, and UOC24pre levels were significantly higher in the REC group than in the NREC-A. There was a tendency towards lower $\mathrm{s}-\mathrm{Cr}$ and higher creatinine clearance at $24 \mathrm{~h}$ after CRRT discontinuation in the REC group compared to the NREC-A group. Number of days 


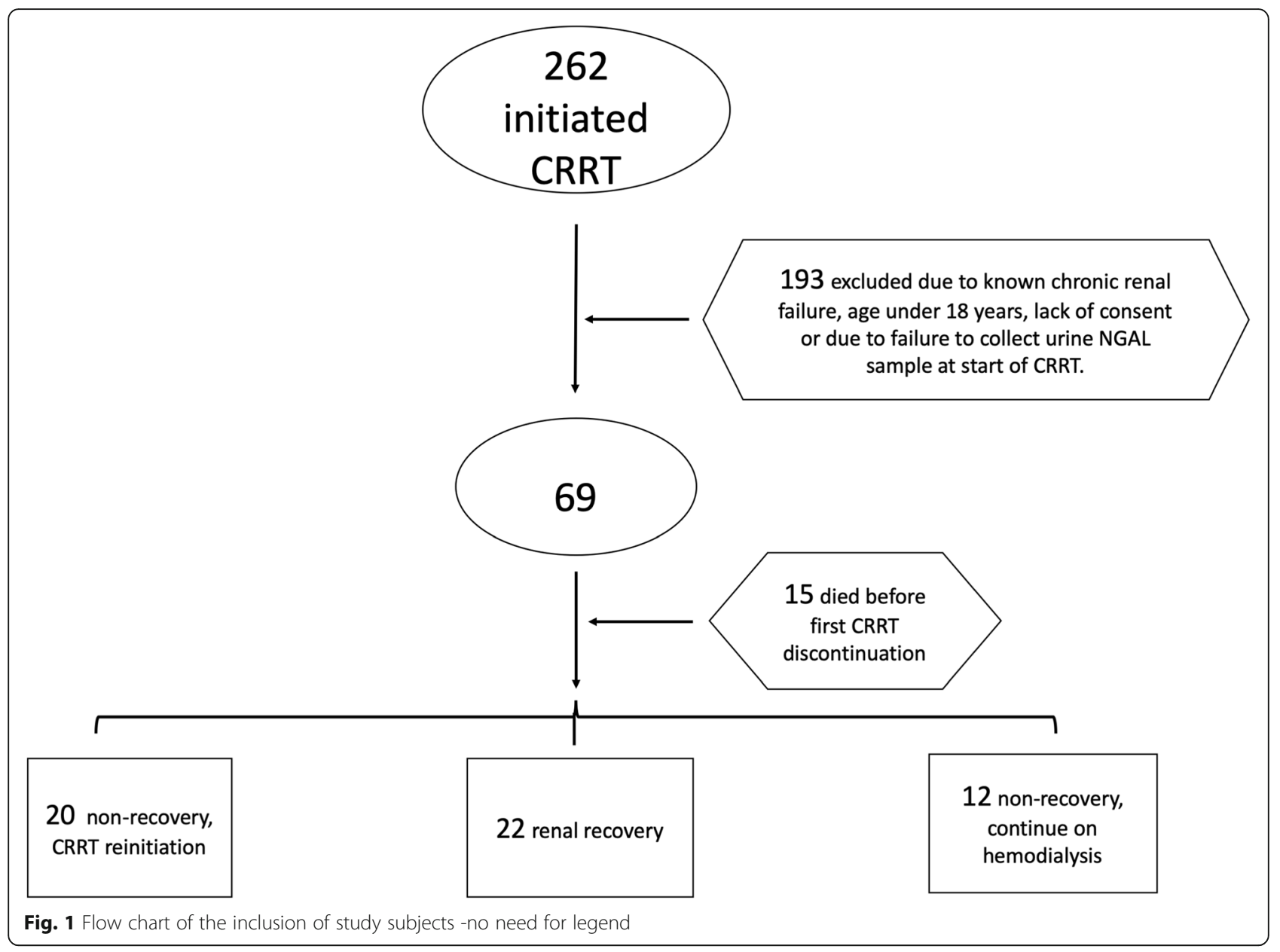

on CRRT before discontinuation was significantly lower in the REC group.

Notable differences between the NREC-H and NREC$\mathrm{C}$ groups is that the NREC-H group displayed an 8 -fold lower mean UNGAL $24 \mathrm{~h}$, and also a 5 -fold lower mean value of UOC24pre compared to that of the NREC-C group. However, none of these differences reached statistical significance.

A comparison of REC versus NREC-C and REC versus NREC-H can be found in the appendix.

Out of the 345 potential samples, 214 (62\%) urine samples were obtained for NGAL analysis. Fifty-seven samples were lost because the patient died while on dialysis, 30 samples were not obtained due to anuria, 31 samples were not collected (forgotten), and 13 samples were missed because dialysis was reinitiated less than 24 $\mathrm{h}$ after discontinuation.

There was a good statistical correlation between $\log$ uNGAL $6 \mathrm{~h}$ and $\log$ uNGAL $0 \mathrm{~h}\left(\mathrm{r}^{2}=0.81\right)$ and between $\log$ uNGAL $6 \mathrm{~h}$ and $\log \mathrm{uNGAL} 12 \mathrm{~h}\left(\mathrm{r}^{2}=0.79\right)$, indicating that missing uNGAL $6 \mathrm{~h}$ or $\mathrm{uNGAL} 0 \mathrm{~h}$ values could be interpolated using the aforementioned linear regression models. From interpolation based on the UNGAL 0 $\mathrm{h}$ values, 13 interpolated uNGAL $6 \mathrm{~h}$ values were obtained. Likewise, based on the UNGAL $12 \mathrm{~h}$ values, 1 interpolated UNGAL 6 h value was obtained. Finally, based on the UNGAL $6 \mathrm{~h}$ values, 8 interpolated uNGAL $0 \mathrm{~h}$ values were obtained. Thus, 51 uNGAL $6 \mathrm{~h}$ and 50 uNGAL $0 \mathrm{~h}$ values were available for further analysis. The 3 missing uNGAL $6 \mathrm{~h}$ values were associated with patients in the NREC-A group, all of whom had a UOC24pre $<100 \mathrm{~mL}$.

The overall ICU mortality was $46 \%$ (29 patients). At 3 months after ICU discharge, the mortality rate increased to $55 \%$ (38 patients). Among the 31 patients who were alive 3 months after ICU discharge, only 2 required dialysis.

The area under the ROC curve (AUC), sensitivity and specificity, NPV, and PPV for the different urine outputs and UNGAL values for the prediction of the successful discontinuation of CRRT are presented in Table 3. For uNGAL $12 \mathrm{~h}$ and UNGAL $24 \mathrm{~h}$, AUC based on the ROCcurves were 0.82 and 0.64 , respectively. However, due to high fractions of missing samples - which were not accessible for interpolation - of UNGAL at these two time points (uNGAL $12 \mathrm{~h}$ : 15/54 samples and UNGAL $24 \mathrm{~h}$ 
Table 2 Variables at the time of discontinuation of continuous renal replacement therapy

\begin{tabular}{|c|c|c|c|c|c|}
\hline Variablep & $n$ & Recovery $(n=22)$ & $\begin{array}{l}\text { Non-recovery; CRRT } \\
\text { re-initiation }(n=20)\end{array}$ & $\begin{array}{l}\text { Non-recovery; Haemodialysis } \\
\text { initiation }(n=12)\end{array}$ & $p$-value \\
\hline \multicolumn{6}{|l|}{ Urine NGAL } \\
\hline time $0, \mu \mathrm{g} / \mathrm{L}$ & 42 & 1370 [154-8002] & $8934[2095-40,000]$ & $8726[360-35,449]$ & $0.0003^{d}$ \\
\hline $6 \mathrm{~h}, \mu \mathrm{g} / \mathrm{L}$ & 37 & 465 [56-3978] & $2966[1985-29,011]$ & 2854 [120-6055] & $0.0006^{d}$ \\
\hline $12 \mathrm{~h}, \mu \mathrm{g} / \mathrm{L}$ & 39 & 436 [95-3780] & $1976[798-16,972]$ & 2148 [54-3825] & $0.0008^{d}$ \\
\hline $24 \mathrm{~h}, \mu \mathrm{g} / \mathrm{L}$ & 31 & 455 [100-3337] & $2290[874-17,665]$ & 295 [32-1624] & $0.24^{d}$ \\
\hline \multicolumn{6}{|l|}{ MAP } \\
\hline time $0, \mathrm{mmHg}$ & 54 & 80 [67-103] & 71 [62-94] & 82 [67-96] & 0.12 \\
\hline $6 \mathrm{~h}, \mathrm{mmHg}$ & 52 & 78 [66-105] & 73 [66-105] & 78 [64-106] & $0.30^{d}$ \\
\hline $12 \mathrm{~h}, \mathrm{mmHg}$ & 50 & 75 [67-106] & 73 [65-105] & 80 [68-103] & 0.42 \\
\hline $24 \mathrm{~h}, \mathrm{mmHg}$ & 46 & 75 [67-106] & 75 [67-103] & 83 [68-113] & 0.60 \\
\hline \multicolumn{6}{|l|}{ Furosemide } \\
\hline $6 \mathrm{~h} ., \mathrm{mg}$ & 52 & $70[0-240]$ & 70 [0-246] & $5[0-240]$ & 0.94 \\
\hline $12 \mathrm{~h} ., \mathrm{mg}$ & 50 & $95[0-480]$ & $95[0-480]$ & $65[0-480]$ & 0.66 \\
\hline 24 h., mg & 46 & 150 [0-853] & 240 [15-936] & 70 [0-936] & 0.50 \\
\hline Use of other diuretics & & $4(18 \%)$ & $4(20 \%)$ & $6(50 \%)$ & 0.52 \\
\hline $\begin{array}{l}\text { Urine output } 24 \mathrm{~h} \text { prior to CRRT (time 0) } \\
\text { discontinuation, } \mathrm{ml}\end{array}$ & 54 & 500 [87-2140] & 100 [31-533] & $20[0-575]$ & $<0.0001$ \\
\hline \multicolumn{6}{|l|}{ Urine output after discontinuation } \\
\hline $6 \mathrm{~h}, \mathrm{ml} / \mathrm{hr}$ & 52 & $65[13-266]$ & $8[0-47]$ & $3[0-50]$ & $<0.0001$ \\
\hline $12 \mathrm{~h}, \mathrm{ml} / \mathrm{hr}$ & 50 & $85[27-197]$ & $10[0-60]$ & $3[0-54]$ & $<0.0001$ \\
\hline $24 \mathrm{~h}, \mathrm{ml}$ & 46 & 2340 [828-4488] & $480[0-2952]$ & $240[0-3828]$ & $<0.0001$ \\
\hline Time to re-initiation of dialysis, hrs & & & $24[6-64]$ & $48[20-71]$ & \\
\hline Time on CRRT, days & 54 & $4[2-10]$ & $8[4-20]$ & $5[2-18]$ & $0,001^{d}$ \\
\hline Mechanical ventilation, days & 54 & $4[0-23]$ & $14[0-32]$ & $2[0-18]$ & 0.18 \\
\hline ICU, days & 54 & $10[2-32]$ & $17[5-38]$ & 9 [3-20] & 0.22 \\
\hline \multicolumn{6}{|l|}{ Creatinine } \\
\hline At discontinuation, $\mu \mathrm{mol} / \mathrm{L} 24 \mathrm{~h}$ after & 54 & $98[51-250]$ & 130 [67-289] & $157[82-314]$ & 0.18 \\
\hline discontinuation, $\mu \mathrm{mol} / \mathrm{L}$ & 46 & $134[67-340]$ & 191 [119-409] & 235 [135-433] & 0.03 \\
\hline \multicolumn{6}{|l|}{ Creatinine clearance } \\
\hline At discontinuation, $\mathrm{ml} / \mathrm{min} 24 \mathrm{~h}$ after & 54 & 62 [17-90] & $43[21-85]$ & 37 [18-75] & 0.08 \\
\hline discontinuation, $\mathrm{ml} / \mathrm{min}$ & 46 & 38 [16-82] & 28 [15-52] & $22[12-41]$ & 0.02 \\
\hline \multicolumn{6}{|l|}{ C-reactive protein (CRP) } \\
\hline At discontinuation, mg/L $24 \mathrm{~h}$ after & 54 & 135 [35-267] & 89 [22-260] & 80 [16-172] & 0.09 \\
\hline discontinuation, mg/L & 46 & 125 [26-238] & $100[20-320]$ & 65 [13-152] & 0.28 \\
\hline
\end{tabular}

P-value was calculated between the recovery and non-recovery (CRRT-re-initiation and haemodialysis) groups. d) Log10 transformation was used to calculate the $p$-value

21/54 samples), uNGAL $12 \mathrm{~h}$ and uNGAL $24 \mathrm{~h}$ were not further explored as test variables.

\section{Performance of single variable diagnostic tests}

Of the single variable diagnostic tests described in Table 3, the best test using uNGAL was uNGAL $6 \mathrm{~h}$ having slightly better AUC, specificity and sensitivity (0.862 vs. 0.857$)$ and also slightly better NPV. The best diagnostic test overall according to Youden's index was
OUA 12 (Youden's index $=0.724$ ) followed by OUC24pre (Youden's index $=0.679$ ). The latter also demonstrated by far the best sensitivity and NPV. When exploring the diagnostic performance of all permutations of 2 -variable tests combining a UNGAL test with one of the tests for urine output using "or" and "and" operators (16 combinations), the highest Youden's index and the highest sensitivity was seen for the combinations of uNGAL $6 \mathrm{~h}$ with UOC24pre. 


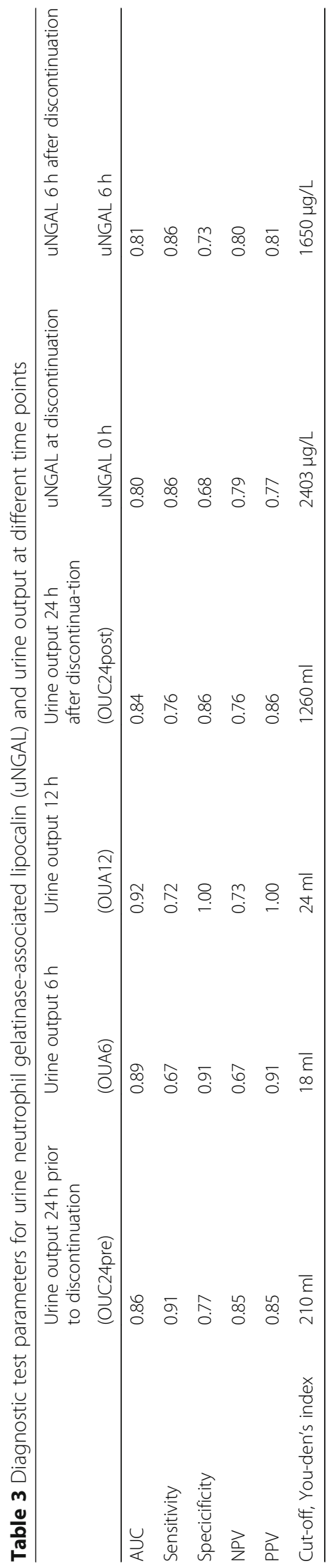




\section{Performance of diagnostic tests combining uNGAL $6 \mathrm{~h}$ with UOC24pre}

The "or" combination of uNGAL at $6 \mathrm{~h}$ and UOC24pre yielded the best sensitivity (0.97) and NPV (0.93). The 2variable test combinations of uNGAL $6 \mathrm{~h}$ and UOC24pre using the cut-off values based on Youdens's index (see Table 3) are presented in Table 4. The NRI (increment in Youden's index) for the uNGAL $6 \mathrm{~h}$ and OUC24pre 2 -variable models in Table 4 as compared to either of the single variable models of uNGAL $6 \mathrm{~h}$ and UOC24pre were:

$$
\begin{aligned}
& \text { uNGAL } 6 \mathrm{~h} \text { or OUC24pre vs. UNGAL } 6 \mathrm{~h}(0.966+ \\
& 0.591)-(0.862+0.727)=-0.033 \\
& \text { uNGAL } 6 \mathrm{~h} \text { and OUC24pre vs UNGAL } 6 \mathrm{~h}(0.793+ \\
& 0.909)-(0.862+0.727)=0.113 \\
& \text { uNGAL } 6 \mathrm{~h} \text { or OUC24pre vs. UOC24pre }(0.966+ \\
& 0.591)-(0.906+0.733)=-0.123 \\
& \text { uNGAL } 6 \mathrm{~h} \text { and OUC24pre vs OUC24pre }(0.793+ \\
& 0.909)-(0.906+0.733)=0.023
\end{aligned}
$$

Thus, only the "and" combination of the 2-variable model showed increased overall diagnostic performance when compared to the single parameter models. However, the "or" combination demonstrated the highest sensitivity and this test combination is therefore the best predictor for successful CRRT discontinuation.

A ROC curve comparing uNGAL 6-h and UOP24pre is available in the appendix.

\section{Discussion}

In this prospective study, it was shown that for ICU patients with complex causes of AKI, UNGAL in combination with urine output was a better predictor of renal function recovery than either applied as a single variable test. Relative to the cessation of CRRT, the best prediction (NPV) of successful CRRT discontinuation was $93 \%$, and was obtained with UNGAL $6 \mathrm{~h}$ combined with OUC24pre. Similarly, the best prediction (PPV) of continued need of dialysis was $92 \%$ and was obtained using the same two variables, but in another combination (Table 4).

The main implication of this is that, although uNGAL as a single variable was not shown to be diagnostically superior to urine output, it did add to the predictive ability of the latter. As such, this study may be taken as a proof of concept that uNGAL is a significant paraclinical parameter with regard to the evaluation of renal recovery and successful CRRT discontinuation in ICU patients.

Technically, the combination of uNGAL $6 \mathrm{~h}$ and UOC24pre (using the "and" operator) was a superior diagnostic test (increase in NRI) compared to either of the single variable models, uNGAL $6 \mathrm{~h}$ and UOC24pre. The test combination of uNGAL $6 \mathrm{~h}$ and UOC24 pre (using the "or" operator), however, had superior sensitivity and was therefore the better diagnostic test to predict successful CRRT discontinuation, although it was inferior (decrease in NRI) to the single variable tests.

Being able to predict the state of non-recovery in ICU dialysis patients as early as $6 \mathrm{~h}$ after CRRT discontinuation has several potential benefits. In addition to the benefit of reducing the time a given patient is without obligatory dialysis, there may also be an economic benefit by avoiding unnecessarily replacement of the dialysis filter.

We arbitrarily chose a "positive" test outcome to associate with continued renal failure (and dialysis dependency). Consequently, a "negative" diagnostic test using uNGAL and/or urine output (Tables 3 and 4) is a predictor of renal recovery (successful CRRT discontinuation).

The procedure in the ICU from which the patients in

\begin{tabular}{|c|c|c|c|c|}
\hline \multirow[t]{2}{*}{ Test } & \multicolumn{2}{|c|}{ uNGAL $>1650 \mu \mathrm{g} / \mathrm{L}$ or urine output $<210 \mathrm{ml}$} & \multicolumn{2}{|c|}{$\mathrm{uNGAL}>1650 \mu \mathrm{g} / \mathrm{L}$ and urine output $<210 \mathrm{ml}$} \\
\hline & Non-recovery & Recovery & Non-recovery & Recovery \\
\hline Test positive & 28 & 9 & 23 & 2 \\
\hline Test negative & 1 & 13 & 6 & 20 \\
\hline Sensitivity & 0.97 & & 0.79 & \\
\hline Specificity & 0.59 & & 0.91 & \\
\hline NPV & 0.93 & & 0.77 & \\
\hline PPV & 0.76 & & 0.92 & \\
\hline
\end{tabular}
this study were recruited is that only patients who are ready to be discharged may be transferred from CRRT to HD. It follows that to initiate haemodialysis, the patient must have infection/inflammatory control and no longer require vasopressor or respiratory support. In this

Table 4 Test parameters and results of diagnostics tests combining the two variables, urine neutrophil gelatinase-associated lipocalin at $6 \mathrm{~h}$ (uNGAL $6 \mathrm{~h}$ ) and urine output $24 \mathrm{~h}$ before CRRT discontinuation (OUC24pre)

Each of the 2 tests are to be seen as a complete diagnostic test with 2 variables. E.g., for "uNGAL $>1650$ um/L or urine output $<210 \mathrm{ml}$ " the test is positive, if either or both "uNGAL $>1650$ " or "urine output $<210 \mathrm{ml}$ " are true. The test is negative if neither of "uNGAL $>1650$ " or "urine output $<210 \mathrm{ml}$ " are true. PPV = positive predictive value; $N P V=$ negative predictive value 
situation, the laboratory parameters indicating inflammation, including UNGAL, are expected to be low. To elaborate, patients eligible to initiate HD are past or almost past the phase of inflammation and acute kidney damage, i.e., the uNGAL level is declining or low, but the kidney function as assessed by serum creatinine, creatinine clearance and urine output is still not satisfactory.

If, in theory, it was possible to identify patients in need of haemodialysis at a point before CRRT cessation, the NPV of the combined UNGAL $6 \mathrm{~h} / \mathrm{OUC} 24$ pre test in our setting would be $100 \%$, as 1 out of 14 patients with a negative test became permanently haemodialysis dependent (Table 4).

To date, only a very few studies have examined the ability of UNGAL to predict renal function recovery after dialysis in critically ill patients. In the study by Yang et al. [14], 102 patients were enrolled, and 8 biomarkers, including uNGAL, were analysed at $24 \mathrm{~h}$ after the discontinuation of dialysis. At 60 days after discontinuation, renal recovery was defined as a serum creatinine level $<0.5 \mathrm{mg} / \mathrm{dl} \quad(84.2 \mu \mathrm{mol} / \mathrm{L})$. The ability of UNGAL to predict renal recovery at this time point was poor, with an AUC of 50\% [14]. However, Yang et al.'s [14] main purpose for measuring uNGAL was not, as in this study, the determination of the immediate need to restart dialysis but prognosticate lasting damage to the kidney. Another study [Biological Markers of Recovery for the Kidney (BioMark)] by Srisawat et al. [15] also indicated the ability of uNGAL to predict more lasting kidney damage. Finally, a study from 2019 by Stads et al. [16] included 92 patients and tested 7 variables, including uNGAL 2 days after the discontinuation of dialysis. Renal recovery was defined as freedom from dialysis 7 days after discontinuation. Urine NGAL was not significantly associated with renal recovery. However, it should be considered whether this study has clinical relevance. It is likely that, at 2 days after discontinuation, the physician already had a very good inclination of the need for dialysis.

There are several limitations of our study. The major limitation was the small number of included patients. This has 2 implications. With a limited number of patients in the different subgroups of recovery and non-recovery, the cut-off limits for uNGAL $6 \mathrm{~h}$ and UOC24pre become less certain, since the range of values of either inevitably will contain gaps rather than representing an unbroken continuum. With regard to the cut-off values representing the best NPV of the combined parameters, uNGAL $6 \mathrm{~h}$ at $1650 \mu \mathrm{g} / \mathrm{L}$ and UOC24pre at $210 \mathrm{~mL}$ were flanked by values of $1327 \mu \mathrm{g} / \mathrm{L}$ and $1863 \mu \mathrm{g} / \mathrm{L}$ and by 195 and $228 \mathrm{~mL}$, respectively. The true cut-off values for the two parameters may therefore in reality lie close to one of their flanking values at either end. The other uncertainty arising from the limited number of patients is the confidence in the calculated NPV and PPV values given in Table 4. For example, the NPV at $93 \%$ is based on the ratio of $13 / 14$ patients and will thus - based on the binomial distribution - have a $90 \%$ one-sided lower confidence limit at $75 \%$. In conclusion, a larger study with more included patients is needed to confirm the findings of this study. Excluding or reclassifying (from "recovery" to "non-recovery") the patient who was placed back on CRRT after $92 \mathrm{~h}$ did not significantly impact the uNGAL $6 \mathrm{~h} /$ UOC24pre prediction model.

Secondly, a number of urine samples were missed for a multitude of reasons. This was mitigated by extrapolating 14 out of 51 values for uNGAL $6 \mathrm{~h}$ from either uNGAL $0 \mathrm{~h}$ or UNGAL $12 \mathrm{~h}$ using linear regression. Despite solid statistically significant correlations between log uNGAL $6 \mathrm{~h}$ values with those at $0 \mathrm{~h}$ and at $12 \mathrm{~h}$, this is a source of uncertainty with regard to the true numeric value of the interpolated uNGAL $6 \mathrm{~h}$ values. However, the UNGAL $0 \mathrm{~h}$ and UNGAL $12 \mathrm{~h}$ values from which the uNGAL $6 \mathrm{~h}$ values were interpolated, yields the exact same test results in relation to UNGAL $0 \mathrm{~h}$ and $\mathrm{UNGAL}$ $12 \mathrm{~h}$ cut-off values, respectively, as is the case for the interpolated uNGAL $6 \mathrm{~h}$ values in relation to the uNGAL $6 \mathrm{~h}$ cut-off value. Therefore, interpolation did not change the conclusion of diagnostic test based on UNGAL $6 \mathrm{~h}$, but it did allow for the "alignment" of all 51 uNGAL results to the $6 \mathrm{~h}$ time point.

The main strength of the study is that it focused on the main clinical issue, i.e., the turning point at which the physician acts and discontinues CRRT. How soon can the physician obtain a reliable estimate of whether the patient has regained renal function or whether dialysis has to be reinitiated? The study showed that the use of two variables, UNGAL and urine output, had greater clinical usefulness than the use of either variable as a single test. The generalizability of the study results appears to be quite good, especially because the included AKI patients were selected broadly. However, the results should be used with care in ICUs in which furosemide is given routinely while the patients are on dialysis.

\section{Conclusions}

In the setting of a multidisciplinary ICU with patients who have complex causes underlying acute kidney failure, a predictive value of $93 \%$ for successful CRRT discontinuation was obtained with a combination of UNGAL at $6 \mathrm{~h}$ and cumulated urine output for $24 \mathrm{~h}$ prior to discontinuation, with cut-offs of $1650 \mu \mathrm{g} / \mathrm{L}$ and $210 \mathrm{~mL}$, respectively. 


\section{Supplementary information}

Supplementary information accompanies this paper at https://doi.org/10. 1186/s12882-020-02035-w.

Additional file 1. Appendix

\section{Abbreviations}

REC: Renal recovery; NREC-A: Non-recovery, all; NREC-H: Non-recovery, haemodialysis; NREC-C: Non-recovery; CRRT; UOC24pre: Cumulated urine output for $24 \mathrm{~h}$ prior to CRRT cessation; UOC24post: Cumulated urine output for $24 \mathrm{~h}$ after CRRT discontinuation; UOA6: Average hourly urine output the first $6 \mathrm{~h}$ after discontinuation; UOA12: Average hourly urine output the first $12 \mathrm{~h}$ after cessation

\section{Acknowledgements}

We acknowledge Sian Robinson for the idea for this study.

\section{Authors' contributions}

JT collected the data. US and JT contributed to the design, analysis and interpretation of the data and the drafting and revision of the manuscript and gave approval for the final version. PT contributed to the design and approval of the final version.

\section{Funding}

The study was partly funded by a grant from the University of Southern Denmark (consultants' research fund at DKK 10.000).

\section{Availability of data and materials}

The datasets used and/or analysed during the current study are available from the corresponding author on reasonable request.

\section{Ethics approval and consent to participate}

The study protocol was approved by the Danish National Committee on Health Research Ethics (reference number: S-20160015), and the process of collecting and storing patient data was approved by the Danish Data Protection Agency (reference number16/1422). Patient informed consent was obtained according to Danish law.

\section{Consent for publication}

We give consent for publication.

\section{Competing interests}

The authors declare that they have no competing interests.

\section{Author details}

${ }^{1}$ Department of Anaesthesiology and Intensive Care, Odense University Hospital, Odense, Denmark. ${ }^{2}$ Department of Clinical Immunology, Odense University Hospital, Odense, Denmark.

Received: 16 April 2020 Accepted: 20 August 2020

Published online: 28 August 2020

\section{References}

1. Hoste EA, Bagshaw SM, Bellomo R, Cely CM, Colman R, Cruz DN, et al. Epidemiology of acute kidney injury in critically ill patients: the multinational AKI-EPI study. Intensive Care Med. 2015;41:1411-23.

2. Katayama S, Uchino S, Uji M, Ohnuma T, Namba Y, Kawarazaki H, et al. Factors predicting successful discontinuation of continuous renal replacement therapy. Anaesth Intensive Care. 2016;44:453-7.

3. Romero-González G, Lorenzin A, Neri M, Ferrari F, Molano-Triviño A, Brendolan A, et al. Discontinuation of continuous renal replacement therapy and dialysis dependence. Contrib Nephrol. 2018;194:118-25.

4. Wu VC, Ko WJ, Chang HW, Chen YW, Lin YF, Shiao CC, et al. Risk factors of early redialysis after weaning from postoperative acute renal replacement therapy. Intensive Care Med. 2008:34:101-8.

5. Heise D, Gries D, Moerer O, Bleckmann A, Quintel M. Predicting restoration of kidney function during CRRT-free intervals. J Cardiothorac Surg. 2012;7:6.

6. Uchino S, Bellomo R, Morimatsu H, Morgera S, Schetz M, Tan I, et al. Discontinuation of continuous renal replacement therapy: a post hoc analysis of a prospective multicenter observational study. Crit Care Med. 2009:37:2576-82.

7. Fröhlich S, Donnelly A, Solymos O, Conlon N. Use of 2-hour creatinine clearance to guide cessation of continuous renal replacement therapy. J Crit Care. 2012;27:744.e1-5

8. de Geus HR, Haase M, Jacob L. The cardiac surgery-associated neutrophil gelatinase-associated lipocalin score for postoperative acute kidney injury: does subclinical acute kidney injury matter? J Thorac Cardiovasc Surg. 2017; 154:939-40.

9. Zhang A, Cai Y, Wang PF, Qu JN, Luo ZC, Chen XD, et al. Diagnosis and prognosis of neutrophil gelatinase-associated lipocalin for acute kidney injury with sepsis: a systematic review and meta-analysis. Crit Care. 2016;20:41.

10. Zhou F, Luo Q, Wang L, Han L. Diagnostic value of neutrophil gelatinaseassociated lipocalin for early diagnosis of cardiac surgery-associated acute kidney injury: a meta-analysis. Eur J Cardiothorac Surg. 2016;49:746-55.

11. Mishra J, Dent C, Tarabishi R, Mitsnefes MM, Ma Q, Kelly C, et al. Neutrophil gelatinase-associated lipocalin (NGAL) as a biomarker for acute renal injury after cardiac surgery. Lancet. 2005;365:1231-8.

12. Haase M, Bellomo R, Devarajan P, Schlattmann P, Haase-Fielitz A, NGAL Meta-analysis Investigator Group. Accuracy of neutrophil gelatinaseassociated lipocalin (NGAL) in diagnosis and prognosis in acute kidney injury: a systematic review and meta-analysis. Am J Kidney Dis. 2009;54: 1012-24.

13. Bennett M, Dent CL, Ma Q, Dastrala S, Grenier F, Workman R, et al. Urine NGAL predicts severity of acute kidney injury after cardiac surgery: a prospective study. Clin J Am Soc Nephrol. 2008;3:665-73.

14. Yang T, Sun S, Zhao Y, Liu Q, Han M, Lin L, et al. Biomarkers upon discontinuation of renal replacement therapy predict 60-day survival and renal recovery in critically ill patients with acute kidney injury. Hemodial Int. 2018:22:56-65.

15. Srisawat $N$, Wen $X$, Lee $M$, Kong $L$, Elder $M$, Carter $M$, et al. Urinary biomarkers and renal recovery in critically ill patients with renal support. Clin J Am Soc Nephrol. 2011;6:1815-23.

16. Stads S, Kant KM, de Jong MFC, de Ruijter W, Cobbaert CM, Betjes MGH, et al. Predictors of short-term successful discontinuation of continuous renal replacement therapy: results from a prospective multicentre study. BMC Nephrol. 2019;20:129.

17. Dankers FJWM, Traverso A, Wee L. Prediction modeling methodology. Cham: Springer; 2019.

\section{Publisher's Note}

Springer Nature remains neutral with regard to jurisdictional claims in published maps and institutional affiliations.

\section{Ready to submit your research? Choose BMC and benefit from:}

- fast, convenient online submission

- thorough peer review by experienced researchers in your field

- rapid publication on acceptance

- support for research data, including large and complex data types

- gold Open Access which fosters wider collaboration and increased citations

- maximum visibility for your research: over $100 \mathrm{M}$ website views per year

At $\mathrm{BMC}$, research is always in progress.

Learn more biomedcentral.com/submission 